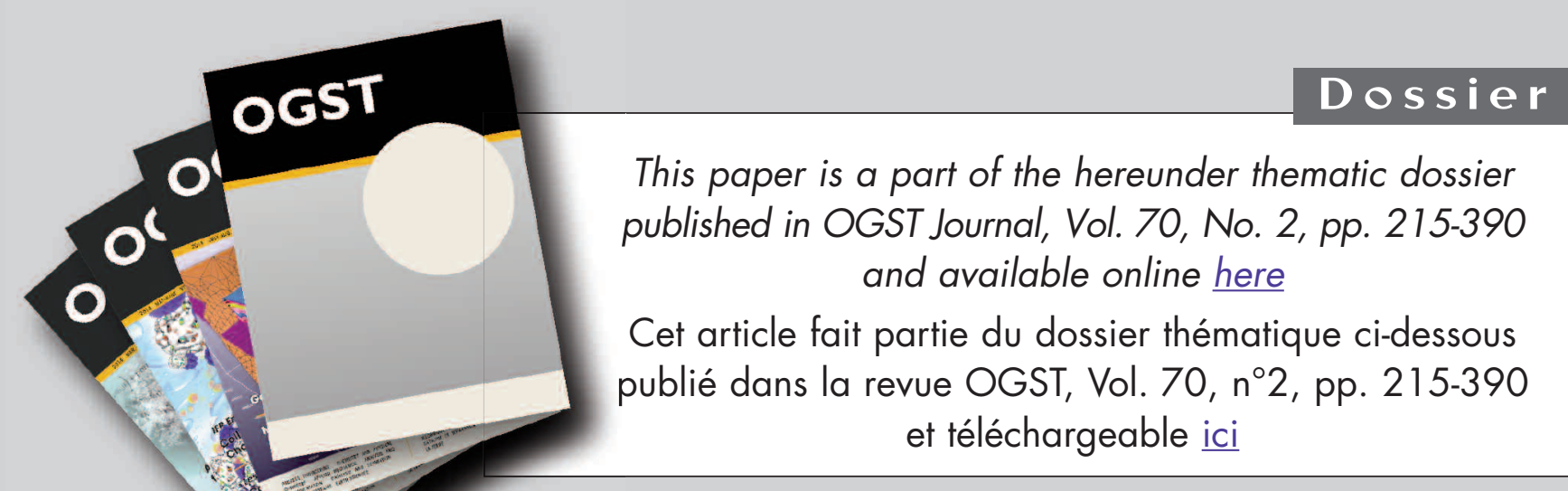

DOSSIER Edited by/Sous la direction de : B. Dewimille

Fluids-Polymers Interactions: Permeability, Durability

Interactions fluides polymères : perméabilité, durabilité

Oil \& Gas Science and Technology - Rev. IFP Energies nouvelles, Vol. 70 (2015), No. 2, pp. 215-390

Copyright (C) 2015, IFP Energies nouvelles

$215>$ Tribute to Yves Chauvin Hommage à Yves Chauvin

S. Candel and 0 . Appert

$219>$ Editorial

G. Kimmerlin

227 > Gas Permeation in Semicrystalline Polyethylene as Studied by Molecular Simulation and Elastic Model

Perméation de gaz dans le polyéthylène semi-cristallin par simulation moléculaire et modèle élastique

P. Memari, V. Lachet and B. Rousseau

237 > Reinforcement of the Gas Barrier Properties of Polyethylene and Polyamide Through the Nanocomposite Approach: Key Factors and Limitations

Renforcement des propriétés barrière aux gaz de matrices polyéthylène et polyamide par l'approche nanocomposite : facteurs clés et limitations E. Picard, J.-F. Gérard and É. Espuche

251 > Diffuso-Kinetics and Diffuso-Mechanics of Carbon Dioxide / Polyvinylidene Fluoride System under Explosive Gas Decompression: Identification of Key Diffuso-Elastic Couplings by Numerical and Experimental Confrontation

Cinétique de diffusion et comportement diffuso-mécanique du système dioxide de carbone / polyfluorure de vinylidène sous décompression explosive de gaz : identification des couplages diffuso-élastiques majeurs par confrontation numérique et expérimentale

J.-C. Grandidier, C. Baudet, S. A. E. Boyer, M.-H. Klopffer and L. Cangémi

267 > Characterization of Polymer Layered Silicate Nanocomposites by Rheology and Permeability Methods: Impact of the Interface Quality

Caractérisation de nanocomposites polymère silicate par des méthodes de rhéologie et de perméabilité : rôle de la qualité de l'interface

R. Waché, M.-H. Klopffer and S. Gonzalez

$279>$ Evaluation of Long Term Behaviour of Polymers for Offshore Oil and Gas Applications

Durabilité des polymères pour application pétrolière offshore

P.-Y. Le Gac, P. Davies and D. Choqueuse

$291>$ Development of Reactive Barrier Polymers against Corrosion for the Oil and Gas Industry: From Formulation to Qualification through the Development of Predictive Multiphysics Modeling

Développement de matériaux barrières réactifs contre la corrosion pour l'industrie pétrolière : de la formulation à la qualification industrielle en passant par le développement de modèles multiphysiques prédictifs

X. Lefebvre, D. Pasquier, S. Gonzalez, T. Epsztein, M. Chirat and F. Demanze
$305>$ Development of Innovating Materials for Distributing Mixtures of Hydrogen and Natural Gas. Study of the Barrier Properties and Durability of Polymer Pipes

Développement de nouveaux matériaux pour la distribution de mélanges de gaz naturel et d'hydrogène. Étude des propriétés barrière et de la durabilité de tubes polymères

M.-H. Klopffer, P. Berne and É. Espuche

317 > New Insights in Polymer-Biofuels Interaction

Avancées dans la compréhension des interactions polymères-biocarburants E. Richaud, F. Diouani, B. Fayolle, J. Verdu and B. Flaconneche

$335>$ Biofuels Barrier Properties of Polyamide 6 and High Density Polyethylene Propriétés barrière aux bio essences du polyamide 6 (PA6) et du polyéthylène haute densité (PEHD)

L.-A. Fillot, S. Ghiringhelli, C. Prebet and S. Rossi

353 > Permeability of EVOH Barrier Material used in Automotive Applications: Metrology Development for Model Fuel Mixtures

Perméabilité d'un matériau barrière EVOH utilisé dans des applications automobiles : développement métrologique pour des mélanges modèles de carburants

J. Zhao, C. Kanaan, R. Clément, B. Brulé, H. Lenda and A. Jonquières

367 > Effects of Thermal Treatment and Physical Aging on the Gas Transport Properties in Matrimid ${ }^{\circledR}$

Les effets du traitement thermique et du vieillissement physique sur les caractéristiques du transport au gaz dans le Matrimid ${ }^{\circledR}$

L. Ansaloni, M. Minelli, M. Giacinti Baschetti and G. C. Sarti

381 > Separation of Binary Mixtures of Propylene and Propane by Facilitated Transport through Silver Incorporated Poly(Ether-Block-Amide) Membranes Séparation de mélanges binaires de propylène et de propane par transport au travers des membranes de poly(éther-blocamide) incorporant de l'argent R. Surya Murali, K. Yamuna Rani, T. Sankarshana, A. F. Ismail and S. Sridhar 


\title{
Permeability of EVOH Barrier Material Used in Automotive Applications: Metrology Development for Model Fuel Mixtures
}

\author{
Jing Zhao', Charbel Kanaan', Robert Clément', Benoît Brulé2, \\ Henri Lenda ${ }^{1}$ and Anne Jonquières ${ }^{1 *}$ \\ ${ }^{1}$ Laboratory of Macromolecular Physical Chemistry, LCPM FRE CNRS-UL 3564, ENSIC, Université de Lorraine, \\ 1 rue Grandville, BP 20451, 54001 Nancy Cedex - France \\ 2 Arkema - CERDATO, rue du Grand Hamel, 27470 Serquigny - France \\ e-mail: jing.zhao@total.com - charbel.kanaan@fr.michelin.com - clement.robert@free.fr - benoit.brule@arkema.com \\ henri.lenda@univ-lorraine.fr - anne.jonquieres@univ-lorraine.fr \\ * Corresponding author
}

\begin{abstract}
Permeability of EVOH Barrier Material Used in Automotive Applications: Metrology Development for Model Fuel Mixtures - EVOH (Ethylene-Vinyl Alcohol) materials are widely used in automotive applications in multi-layer fuel lines and tanks owing to their excellent barrier properties to aromatic and aliphatic hydrocarbons. These barrier materials are essential to limit environmental fuel emissions and comply with the challenging requirements of fast changing international regulations. Nevertheless, the measurement of EVOH permeability to model fuel mixtures or to their individual components is particularly difficult due to the complexity of these systems and their very low permeability, which can vary by several orders of magnitude depending on the permeating species and their relative concentrations. This paper describes the development of a new automated permeameter capable of taking up the challenge of measuring minute quantities as low as $1 \mathrm{mg} /\left(\mathrm{m}^{2}\right.$.day) for partial fluxes for model fuel mixtures containing ethanol, i-octane and toluene at $50^{\circ} \mathrm{C}$. The permeability results are discussed as a function of the model fuel composition and the importance of EVOH preconditioning is emphasized for accurate permeability measurements. The last part focuses on the influence of EVOH conditioning on its mechanical properties and its microstructure, and further illustrates the specific behavior of EVOH in presence of ethanol oxygenated fuels. The new metrology developed in this work offers a new insight in the permeability properties of a leading barrier material and will help prevent the consequences of (bio) ethanol addition in fuels on environmental emissions through fuel lines and tanks.
\end{abstract}

Résumé - Perméabilité d'un matériau barrière EVOH utilisé dans des applications automobiles : développement métrologique pour des mélanges modèles de carburants - Les matériaux EVOH (Ethylene-Vinyl Alcohol) sont largement utilisés dans des tubes et réservoirs multicouches pour les carburants car ils présentent d'excellentes propriétés barrières aux composés hydrocarbonés aromatiques et aliphatiques. Ces matériaux barrières sont essentiels pour limiter les fuites de carburants dans l'environnement et satisfaire aux normes environnementales internationales de plus en plus sévères. Néanmoins, la mesure de la perméabilité de ces matériaux à des mélanges 
modèles de carburants, ou à leurs composants individuels, est particulièrement difficile en raison de la complexité de ces systèmes et de leurs très faibles perméabilités, qui peuvent cependant varier de plusieurs ordres de grandeur selon la nature des espèces transférées et leurs concentrations respectives. Cet article décrit le développement d'un nouveau perméamètre automatisé capable de relever le défi de mesurer des flux partiels aussi faibles que $1 \mathrm{mg} /\left(\mathrm{m}^{2}\right.$.jour $)$ pour des mélanges modèles de carburants contenant de l'éthanol, de l'i-octane et du toluène. Les résultats de perméabilité sont discutés en fonction de la composition des mélanges modèles et l'importance d'un pré-conditionnement des films d'EVOH est soulignée pour obtenir des mesures fiables. La dernière partie se concentre sur l'influence du conditionnement de l'EVOH sur ses propriétés mécaniques et sa microstructure et illustre de façon complémentaire le comportement spécifique de l'EVOH en présence de mélanges modèles de carburants oxygénés. La métrologie développée apporte de nouveaux éléments de compréhension de la perméabilité d'un matériau barrière leader et devrait contribuer à prévenir les conséquences de l'addition de (bio)éthanol dans les carburants sur les émissions environnementales à travers les tubes et réservoirs polymères multicouches.

\section{INTRODUCTION}

Ethylene-vinyl alcohol (EVOH) copolymers are amongst the best commercial barrier materials used worldwide. They are mainly used in packaging applications for their excellent barrier properties to oxygen [1]. The chemical physical properties of EVOH copolymers are highly dependent upon their vinyl alcohol content and the best barrier properties are obtained with high contents in vinyl alcohol $(\geq 68 \%)$. Nevertheless, the content in vinyl alcohol does usually not exceed $80 \%$ because higher contents are responsible for an increased sensitivity to water. The data reported in Table 1 show the very low oxygen permeability of EVOH copolymers compared to other polymer materials commonly used in packaging applications. Nevertheless, the EVOH outstanding barrier performances are highly sensitive to humidity and temperature. Several papers have for instance discussed the influence of humidity on sorption [2, 3], glass transition temperature [4], morphology [5] and permeability properties for packaging applications [2, 6, 7]. Typically, EVOH barrier properties decrease considerably above $75 \%$ relative humidity. Therefore, in packaging applications, the EVOH barrier material is usually co-extruded with hydrophobic polyolefin layers which protect the barrier layer from humidity.

EVOH copolymers are also used in automotive applications in fuel lines and tanks owing to their excellent barrier properties to aromatic and aliphatic hydrocarbons. Polymer fuel lines and tanks usually also involve complex multi-layer structures to limit environmental fuel emissions and comply with the challenging requirements of fast changing international regulations. EVOH copolymers are in the middle of the multi-layer structure and play a key role on the barrier properties. The measurement of $\mathrm{EVOH}$ permeability to model fuel mixtures or to their individual components is particularly difficult due to the complexity of these systems and their very low permeability, which can nevertheless vary by several

TABLE 1

Comparison of the barrier properties of EVOH copolymers to oxygen and model fuels with other common barrier materials [9, 16]

\begin{tabular}{|c|c|c|c|}
\hline & $\begin{array}{c}\text { Oxygen }\left(20^{\circ} \mathrm{C}\right)^{*} \\
\left(\mathrm{~cm}^{3} \cdot \mathrm{cm} / \mathrm{cm}^{3} \cdot \mathrm{s} \cdot \mathrm{cmHg} \cdot 10^{13}\right)\end{array}$ & & $\begin{array}{l}\text { Hydrocarbons }\left(40^{\circ} \mathrm{C}\right) \\
\quad\left(\text { g. } \mathrm{mm} / \mathrm{m}^{2} . \text { day }\right)\end{array}$ \\
\hline EVOH 29 & 0.1 & \multirow{4}{*}{ EVOH 32} & 0.005 (Fuel C) \\
\hline EVOH 38 & 0.4 & & 0.02 (Fuel C $+10 \%$ ethanol) \\
\hline LDPE & 2400 & & 4.5-5.5 (Fuel C $+15 \%$ methanol) \\
\hline HDPE & 1100 & & 0.004 (toluene) \\
\hline Polyamide & 23 & HDPE & 62.6 (Fuel C) \\
\hline PVC & 40 & PA6 & 5.06 (Fuel C) \\
\hline
\end{tabular}

\footnotetext{
* Oxygen permeability for dry state.
}

Note: EVOH $X$ corresponds to an EVOH copolymer containing $X$ mol\% of ethylene and Fuel $\mathrm{C}$ is an equivolumic mixture of toluene and $i$-octane. 
orders of magnitude depending on the permeating species and their relative concentrations.

Related permeability investigations for $\mathrm{EVOH}$ copolymers and model fuels (or their individual components) remain really scarce in the literature [8-11]. Nevertheless, the results reported in Table 1 show the outstanding barrier properties of EVOH copolymers to Fuel $\mathrm{C}$ which is a model fuel commonly used for assessing the permeability properties of fuel lines and tanks in the automotive industry. Fuel $\mathrm{C}$ is an equivolumic mixture of toluene and $i$-octane, both components being representative of the aromatic and aliphatic hydrocarbons in real fuels. When EVOH films were tested in absence of humidity, the fluxes of toluene and $i$-octane could not be detected by Nulman et al. [9] at the Ford Motor Company equipped with a permeation cell connected to a carbon adsorbent trapping and desorbing circuit. Lagaron et al. [10] in collaboration with BP Chemicals Limited succeeded in measuring a very low permeability to toluene for Fuel $\mathrm{C}$ but the permeability to $i$-octane was again not detected on the basis of weight loss measurements for semi-closed permeation cells.

Nevertheless, a few former works have already reported that the EVOH outstanding barrier properties to aromatics and aliphatics were strongly decreased in presence of water and oxygenated species like methanol and ethanol [8-11]. This issue is particularly critical for the automotive industry where increasing amounts of oxygenated species are being added to fuels to minimize the fuel environmental impact and take advantage of the ethanol biofuel. Samus and Rossi [8] have thoroughly analyzed the complex behavior of EVOH with respect to methanol permeability on the basis of sorption, diffusion and dynamic mechanical experiments. They have reported a strong linear decrease of EVOH glass transition temperature as function of methanol weight fraction absorbed in EVOH. The plasticization induced by methanol had an important impact on its permeability which strongly increased above glass transition temperature. Nulman et al. [9] have also reported interesting permeability results for $\mathrm{EVOH}$ and a model fuel methanol/i-octane/toluene $(15 / 42.5 / 42.5$ in vol\% - Fuel CM15). The methanol flux obtained with Fuel CM15 was almost $20 \%$ of that of pure methanol. The authors mentioned that the corresponding fluxes of toluene and $i$-octane were less than $0.01 \mathrm{~g} \mathrm{~mm} /\left(\mathrm{m}^{2}\right.$.day $)$ at $40^{\circ} \mathrm{C}$. Even if the partial fluxes of toluene and $i$-octane could not be quantified for Fuel CM15 at $40^{\circ} \mathrm{C}$, the latter work showed qualitatively that the addition of methanol to Fuel C strongly increased the toluene flux and decreased the overall barrier performance of EVOH. The quantitative permeability data reported by Lagaron et al. [10] further confirmed this observation and showed that the total flux of EVOH was increased by three orders of magnitude by adding $15 \%$ of methanol to Fuel C. Furthermore, when $10 \%$ of ethanol was added to Fuel C, the total flux increased by a factor 4 only, which showed that ethanol had less impact on the EVOH barrier properties than methanol.

Later on, Gagnard et al. [11] in collaboration with the worldwide company Arkema developed an automated permeameter combining a semi-closed permeation cell, a desorption trap and on-line GC-analysis and reported permeability data for several barrier materials used in fuel tank applications. For the first time for an EVOH film, the fluxes of each permeating species (partial fluxes) were determined for methanol/toluene mixtures over the whole composition range. For all the methanol/toluene mixtures, the methanol flux was much higher than the toluene flux. The data also revealed the strong enhancement of the toluene flux over a wide range of compositions in presence of methanol at $60^{\circ} \mathrm{C}$. The maximum toluene flux was obtained for $70 \%$ of methanol and was 2500 times higher than that of pure toluene in the same conditions.

Following our former work for assessing related sorption properties [12], this new paper in collaboration with Arkema describes a new metrology development for measuring the permeability properties of barrier materials used in fuel tank applications. Our first objective was to characterize accurately the partial fluxes for an EVOH copolymer and complex model fuel mixtures containing ethanol, toluene and $i$-octane over a wide composition range typical of the targeted application. As mentioned above, the addition of ethanol in Fuel C leads to a smaller increase in fuel permeation than the addition of methanol. From an experimental point of view, the subject of this paper is more challenging than the measurements formerly performed at Arkema with methanol based fuels. The first part of the paper describes the development of a new automated permeameter capable of taking up the challenge of measuring minute quantities as low as $1 \mathrm{mg} /\left(\mathrm{m}^{2}\right.$.day $)$ for the partial fluxes. The second part of the paper discusses the permeability results as a function of the model fuel composition and emphasizes the importance of EVOH preconditioning for accurate permeability measurements. The last part focuses on the influence of EVOH conditioning on its mechanical properties and its microstructure, and further illustrates the specific behavior of EVOH in presence of ethanol oxygenated fuels. The new metrology developed in this work offers a new insight in the permeability properties of one of the leading barrier polymers for fuel lines and tanks. 


\section{MATERIALS AND METHODS}

\subsection{Solvents and EVOH Copolymer}

Solvents of maximal purity were purchased for this investigation because the presence of impurity can be detrimental to the permeability analysis. Toluene (Aldrich, ACS reagent, $99.5+\%$, boiling point $110.6^{\circ} \mathrm{C}$ ), $i$-octane (Aldrich, ACS reagent, $99+\%$, boiling point $98.5^{\circ} \mathrm{C}$ ) and ethanol (Aldrich, absolute, $99.8+\%$, boiling point $78.5^{\circ} \mathrm{C}$ ) were used without further purification.

The EVOH copolymer was a high barrier material commonly used in multi-layer fuel tanks. This copolymer was an EVOH DT Soarnol® containing $29 \mathrm{~mol} \%$ of ethylene. Table 2 reports its main physical characteristics. In this study, we focused on the permeability properties of EVOH monolayer films, the corresponding data being necessary for a future modeling of their multicomponent permeability. The EVOH films used for the permeability experiments were extruded films produced by Arkema. The film thicknesses were optimized with respect to permeability in order to obtain good accuracy of the partial fluxes for the different compositions of the model fuels.

\subsection{Physical Characterization of EVOH Material}

Differential Scanning Calorimetry (DSC) experiments were carried out with a DSC 2920 TA Instruments with liquid nitrogen cooling. Sample weights were ca. $10 \mathrm{mg}$. EVOH films of $10 \mu \mathrm{m}$ were first heated from $-20^{\circ} \mathrm{C}$ to $250^{\circ} \mathrm{C}$ at a heating rate of $20^{\circ} \mathrm{C} / \mathrm{min}$ then cooled down from $250^{\circ} \mathrm{C}$ to $-20^{\circ} \mathrm{C}$ at the same rate. A second heating was then performed in the same conditions. The data were recorded over the whole cycle with EVOH films before and after preconditioning. During preconditioning for DSC analysis, the $\mathrm{EVOH}$ films were immersed in a model fuel mixture ethanol/i-octane/ toluene $\left(85 / 7.5 / 7.5-\right.$ Fuel CE85) at $40^{\circ} \mathrm{C}$ until saturation

TABLE 2

Main characteristics of the EVOH investigated in this work

\begin{tabular}{c|c}
\hline & $\begin{array}{c}\text { EVOH DT Soarnol }{ }^{\circledR} \\
29 \mathrm{~mol} \% \text { ethylene }\end{array}$ \\
\hline Density $\left(\mathrm{g} / \mathrm{cm}^{3}\right)$ & 1.21 \\
\hline Melting temperature $\left({ }^{\circ} \mathrm{C}\right)$ & 188 \\
\hline Crystallisation temperature $\left({ }^{\circ} \mathrm{C}\right)$ & 163 \\
\hline Glass transition temperature ${ }^{*}\left({ }^{\circ} \mathrm{C}\right)$ & 62 \\
\hline
\end{tabular}

${ }^{*}$ DSC measurement on dry state. was reached and then dried at ambient temperature in air.

Wide Angle X-ray Scattering (WAXS) experiments completed the DSC analysis for assessing the influence of EVOH conditioning on copolymer crystallinity. The spectra were recorded in transmission with EVOH films before and after preconditioning like for the DSC experiments. The spectra were recorded on an INEL equipment with a wavelength defined by the main ray of $K \alpha 1$ of copper (1.54 Angström), an incident energy of $32 \mathrm{kV}$ and a counting time of 3000 seconds. Eight EVOH films of $10 \mu \mathrm{m}$ had to be stacked together to obtain a sufficient signal.

Original Dynamic Mechanical Analysis (DMA) experiments were performed on a DMA 242C Netzsch while the EVOH films were immersed in pure solvents or model fuel mixtures to follow the consequences of conditioning on the mechanical properties in real time. The thickness of the EVOH films had to be increased to $60 \mu \mathrm{m}$ to obtain good DMA sensitivity in these conditions. The experiments were carried out at a frequency of $1.6 \mathrm{~Hz}$ at $50^{\circ} \mathrm{C}$, which corresponded to the temperature used for the permeability experiments. Dynamic Mechanical Thermal Analysis (DMTA) experiments were also carried out to assess the influence of model fuel composition on the temperature of the $\alpha$ transition. In DMTA experiments, the loss factor $\tan \delta$ was recorded at the same frequency of $1.6 \mathrm{~Hz}$ for temperatures increasing from $-40^{\circ} \mathrm{C}$ to $80^{\circ} \mathrm{C}$ with a heating rate of $2^{\circ} \mathrm{C} / \mathrm{min}$.

\subsection{Permeability Experiments}

The permeability experiments were performed with $\mathrm{EVOH}$ films of $8.4 \mathrm{~cm}^{2}$ at $50^{\circ} \mathrm{C}$ with an automated permeameter specifically developed for this purpose in our laboratory (Fig. 1). The thickness of the EVOH films was chosen according to the total permeability in order to optimize the permeability measurements. This permeameter enabled to analyze permeation in a continuous way in a fully closed system by the pervaporation membrane technique. In this membrane process, a model fuel mixture was circulated on top of the EVOH film by a pump from a stainless-steel reservoir at constant temperature. The temperature of $50^{\circ} \mathrm{C}$ was checked in the thermally insulated permeation cell. The downstream side of the EVOH film was maintained under low pressure (typically less than $0.5 \mathrm{~mm} \mathrm{Hg}$ ) by an Adixon vacuum pump. In these conditions, the boundary conditions for mass transfer across the EVOH film were well defined and easily reproducible. The permeate was collected in a sampling loop cooled by a liquid nitrogen trap, which was mounted on a pneumatic jack for automation (Fig. 2). 


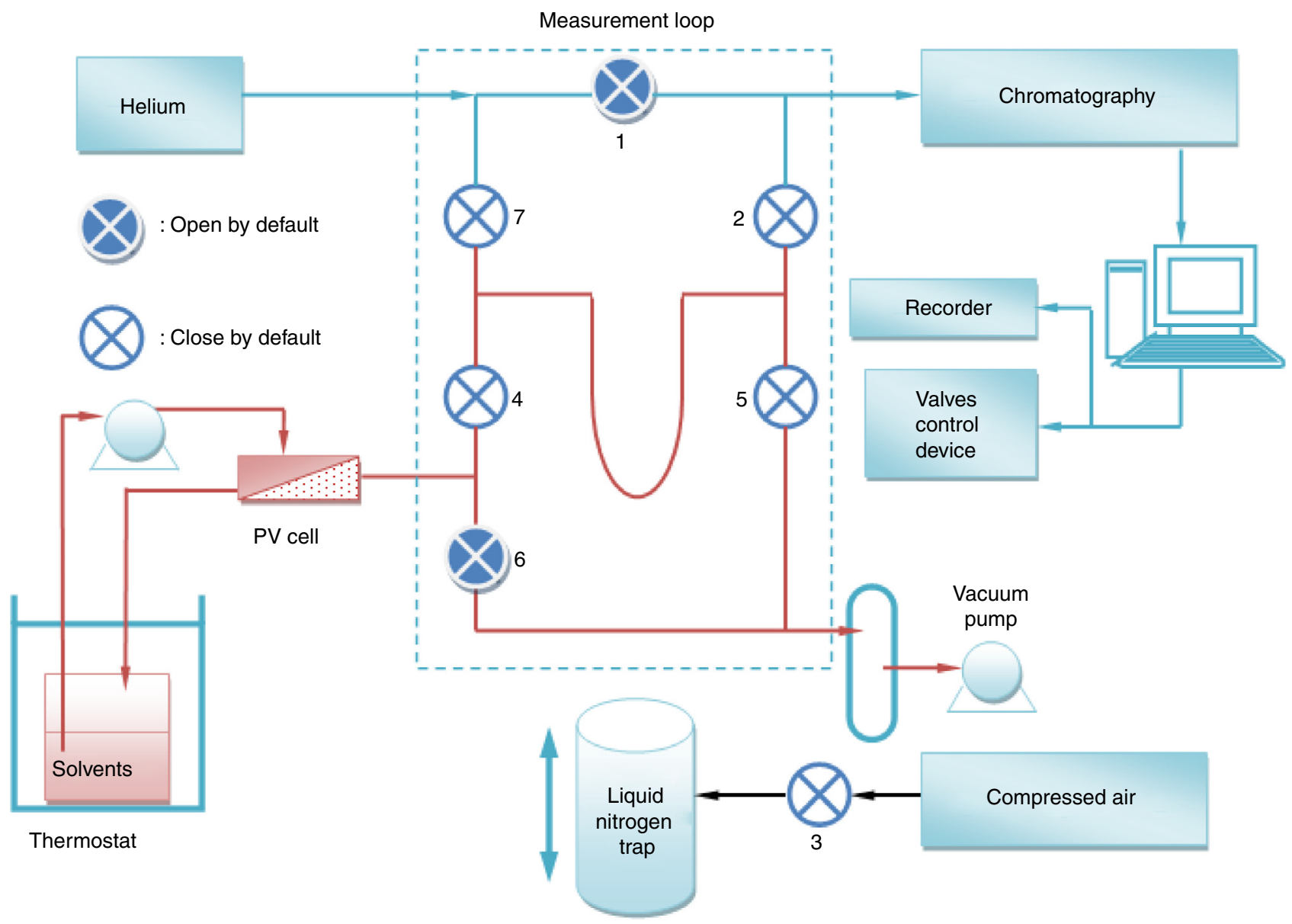

Figure 1

Scheme of the automated experimental set-up developed for permeability measurements with barrier polymer materials and multicomponent fuel model mixtures.

The sampling loop was equipped with on-line gas chromatography (Shimadzu GC 8A/ PDMS SE30 column). The automation of the whole system was performed via solenoid valves (Bacosol inox-teflon valves) which were controlled by a personal computer through an appropriate electronic high sensitivity interface (Keithley KPCI 3107 Data Acquisition Board). The same controller was also used to drive the automated pneumatic jack necessary for the cooling of the measurement loop by liquid nitrogen.

In a typical permeation experiment, the permeate was collected over a limited period of time which depended on the total permeation rate. Each permeation experiment was carried out in several cycles consisting of condensing the permeate vapors in liquid nitrogen, heating the permeate to room temperature followed by on-line chromatography analysis. The sampling time was automatically adjusted from one cycle to another to avoid saturating the GC FID detector and to remain in its linearity range.

A Visual Basic interface was developed to follow the progress of each experiment. Figure 3 gives an example for the computer screen displayed during an experiment. This computer screen showed the state for all the solenoid valves and a plot of the last chromatogram. The weights of each permeated species were obtained from the area of each peak by a preliminary GC absolute calibration. Even if it could have theoretically been done and saved some time, the absolute GC calibration was not performed directly with specific and well chosen fuel mixtures because it would have been quite difficult to find polymer films with moderate permeability for all 


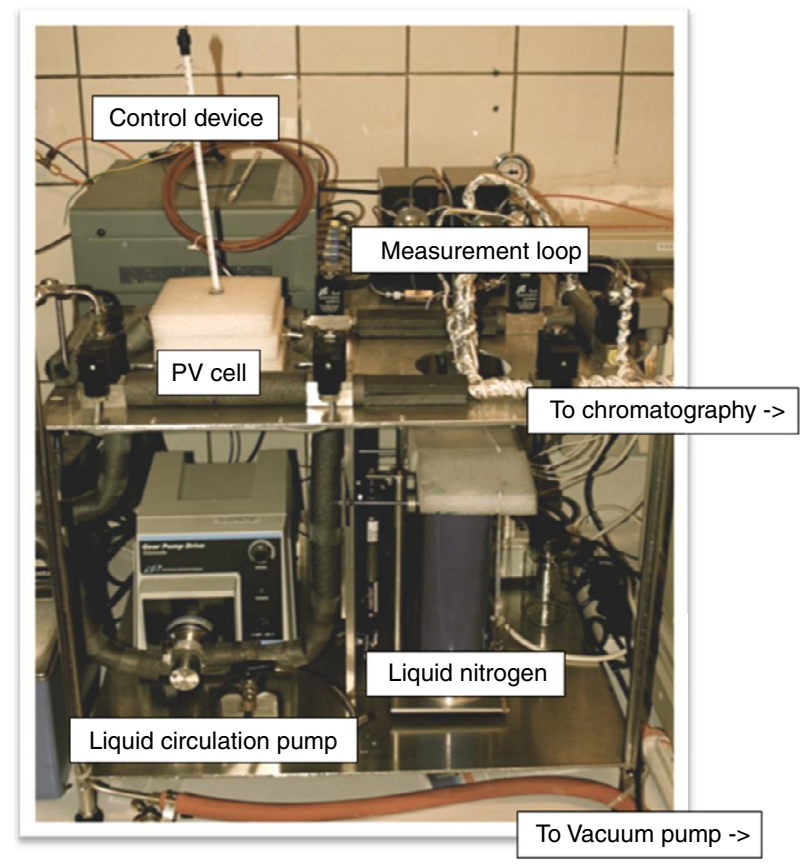

Figure 2

Photograph of the automated permeameter.

of the different components of the fuel mixtures. Therefore, the calibration was made with polymer films having known and moderate permeability for each pure species (i.e. ethanol, $i$-octane and toluene) to minimize the errors made in estimating each calibration coefficient. Knowing the weights of each permeated species $w_{i}$, the sampling time $\Delta t$ and the active membrane area $A_{\text {mem }}$, the partial flux of each species $i$ were calculated by Equation (1):

$$
J_{i}=\frac{w_{i}}{\Delta t} \frac{1}{A_{m e m}}
$$

To optimize the measurements of the different partial fluxes which could differ by several orders of magnitude for the same experiment, the sensitivity range of the gas chromatograph was adapted to the injected weights. With delays of 0.1 second for valve commutation and sampling times of ca. 1 minute, the measurements were repeatable in stationary regime. Furthermore, the permeameter was also equipped with a secondary measurement loop, which enabled on-line analysis of the model fuel composition. With the small membrane area of $8.4 \mathrm{~cm}^{2}$ of the EVOH films used in this work, the permeate sampling did not induce any significant change in the composition of the model fuel mixture with a minimum circulating feed volume of $150 \mathrm{~mL}$.
With this automated permeater, each measurement cycle for the partial fluxes took between 15 to $20 \mathrm{~min}$ utes, depending on the sampling time which was a function of the total permeation rate but never exceeded 300 seconds. Typically, a few hours were generally necessary for obtaining steady-state permeability data for each composition of the model fuel mixture and partial fluxes as low as $1 \mathrm{mg} /\left(\mathrm{m}^{2}\right.$.day) were measured quantitatively.

\section{RESULTS AND DISCUSSION}

\subsection{Permeability Results Obtained for Virgin and Preconditioned EVOH Materials}

The EVOH permeability features were characterized for model fuel mixtures containing ethanol, $i$-octane and toluene. Ethanol (rather than methanol) was chosen in this work because, thanks to different tax policies, this biofuel is being more and more used in European fuels. The permeability data were obtained for two important tie lines of the ternary diagram ethanol $/ i$-octane/toluene with respect to the permeation properties (Fig. 4). The first tie line (called ethanol tie line) corresponded to equivolumic mixtures of toluene and i-octane (i.e. Fuel C) with increasing contents in ethanol. Ethanol contents were limited in the range of 50 to $100 \%$, which corresponded to the working range of an $\mathrm{EVOH}$ layer in a multi-layer fuel tanks as shown by our former sorption measurements for HDPE and EVOH materials [12]. The second tie line (called toluene tie line) corresponded to equivolumic mixtures of ethanol and $i$-octane with increasing contents in toluene. Ethanol and toluene are key species for mass transfer through EVOH and other polymers used in polymer fuel tanks. The corresponding tie lines were chosen to assess the permeability behavior over a wide range of compositions covering a large domain of the ternary diagram and typical of the targeted application.

During metrology development, the first permeability measurements with virgin EVOH films led to partial fluxes which were slightly evoluting over long periods of time. Figure 5 shows an example for the slow decline of the partial fluxes for ethanol, toluene and $i$-octane, even for a relatively thin EVOH film of $25 \mu \mathrm{m}$. The steady-state was very difficult to attain with virgin EVOH films and accurate permeability measurements could not be performed in these conditions no matter the sensitivity of the new automated permeameter. It was also important to maintain vacuum at the downstream side of the EVOH films for whole series of permeability measurements over several weeks. Otherwise, 


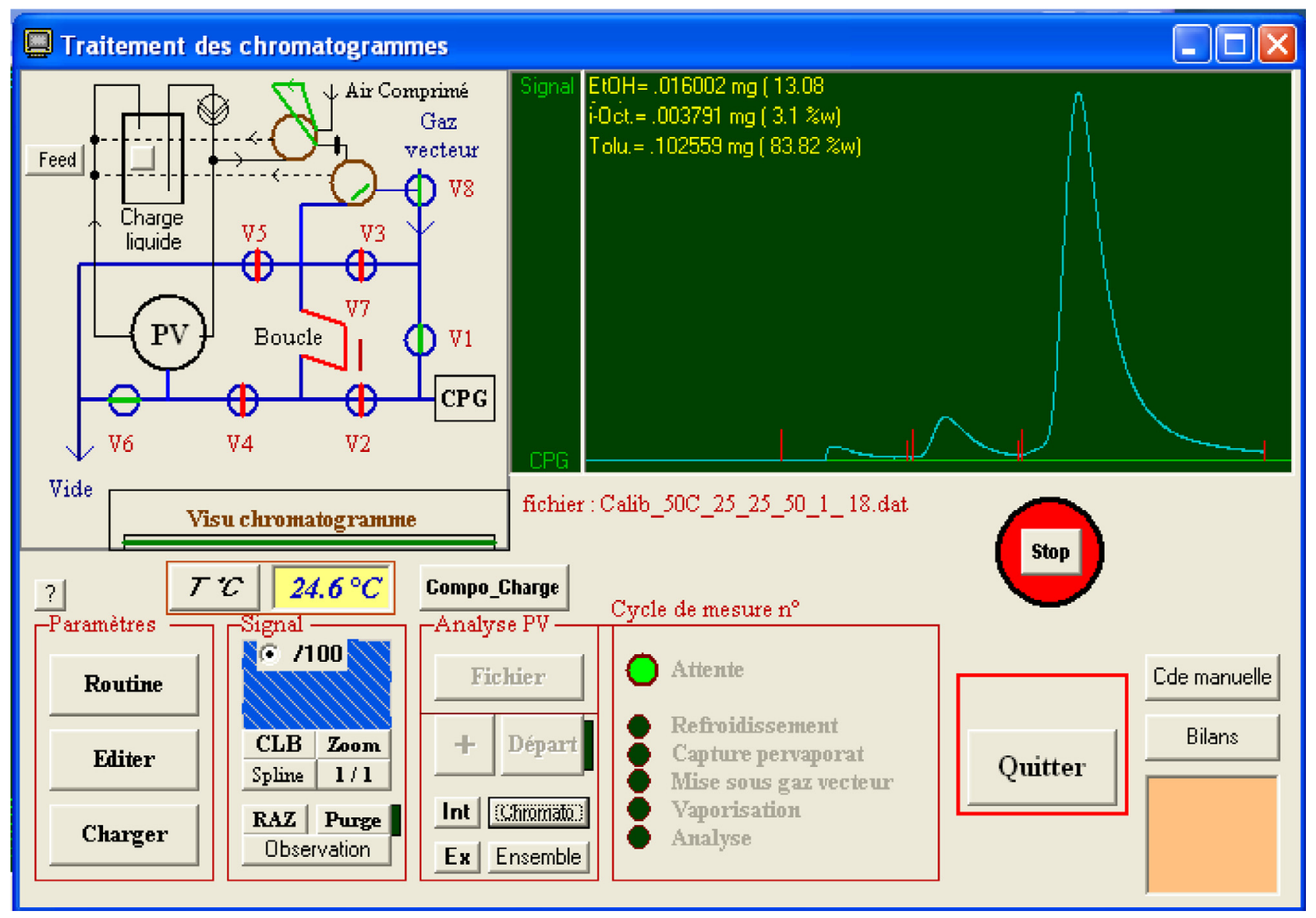

Figure 3

Copy of the computer screen displayed during permeability measurement.

the intermittent swelling of the film downstream side led to significant perturbation in the measured permeability properties (even sometimes to film breaking for the thinnest films) and the come-back to steady-state was again very slow. The preconditioning of the EVOH films in the targeted model fuel mixtures for more than ten days at $50^{\circ} \mathrm{C}$ considerably accelerated the reaching of the permeation steady-state and it became possible to obtain stable permeation data within a few hours for each composition of the model fuel mixtures.

Figure 6 shows the partial fluxes of ethanol, toluene and $i$-octane for a preconditioned EVOH film of $9 \mu \mathrm{m}$ and the ethanol tie line at $50^{\circ} \mathrm{C}$. Ethanol partial fluxes increased with feed ethanol content and were about ten times higher than the toluene partial fluxes. The strong interactions of ethanol with EVOH hydroxyl groups were partially responsible for the high EVOH permeability to ethanol. The permeability to both hydrocarbons were much less than the permeability to ethanol, confirming the very good barrier properties of EVOH to apolar hydrocarbons. These results are in good agreement with those reported by Nulman et al. [9] for Fuel CM15, which also showed the preferential permeation of alcohol (i.e. methanol in that case) through EVOH films. The authors mentioned that the toluene and $i$-octane fluxes were less than $0.01 \mathrm{~g} . \mathrm{mm} / \mathrm{m}^{2} 24 \mathrm{~h}$, which confirmed that EVOH was acting as a very good barrier towards both hydrocarbon species. Nevertheless, the reported data did not allow any comparison between both hydrocarbon species. The same comment could also be made for the data reported by Lagaron et al. [10] for very closely related systems. The new automated permeameter developed in this work offered some progress for $i$-octane flux measurements. For the first time, to the best of our knowledge, Figure 6 enabled a quantitative comparison between the partial fluxes of toluene and $i$-octane. These partial fluxes differed by one order of magnitude over the whole composition range investigated for the ethanol tie line. Although these new data cannot be compared to former related $\mathrm{EVOH}$ permeability data, it is well known from 


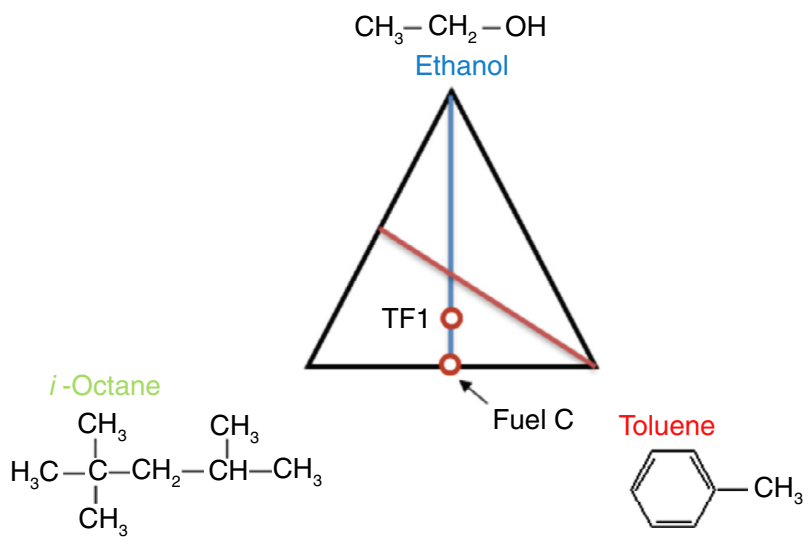

Ethanol tie line : EtOH/i-octane/toluene (x/y/y vol\%) Toluene tie line : $\mathrm{EtOH} / i$-octane/toluene ( $\mathrm{x} / \mathrm{x} / \mathrm{y}$ vol\%) TF1 fuel mixture $\mathrm{EtOH} / i$-octane/toluene (10/45/45 vol\%) Fuel C $i$-octane/toluene (50/50 vol\%)

Figure 4

The model fuel mixtures investigated in this work in the ternary diagram ethanol $/ i$-octane/toluene in comparison with model fuels $\mathrm{C}$ and TF1 commonly used in this field.

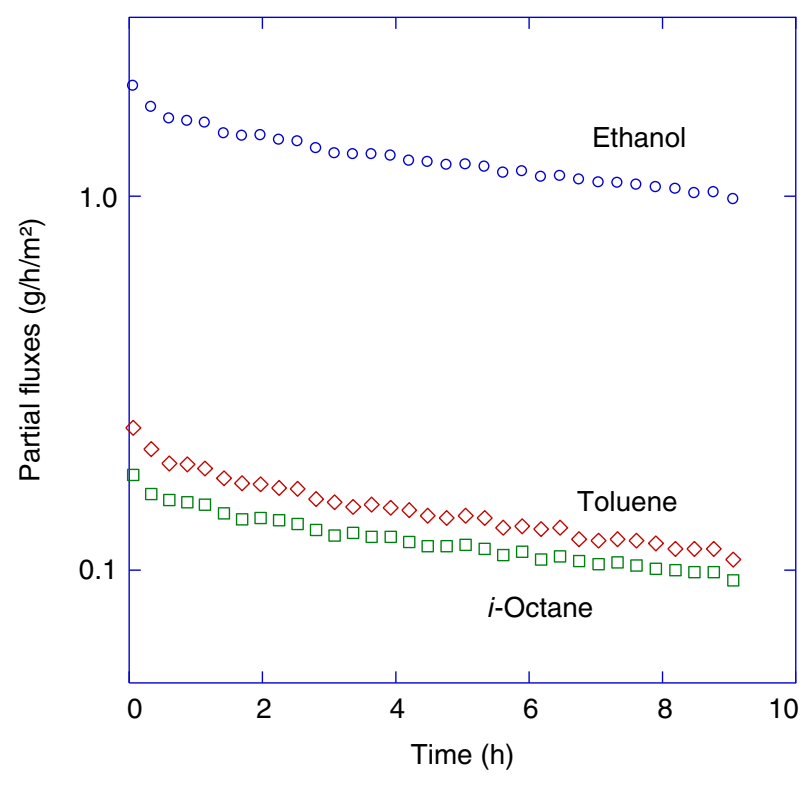

Figure 5

Evolution of the partial fluxes of a virgin EVOH film of $25 \mu \mathrm{m}$ for a model fuel mixture ethanol/i-octane/toluene $(12.5 / 12.5 / 75 \mathrm{vol} \%)$ at $50^{\circ} \mathrm{C}$.

the literature on the separation of aromatics/alkanes mixtures by membrane separation processes that polar polymers are usually used for this type of separation [13-15]. Such polymers are indeed capable of interacting with aromatics owing to their strong polarizability.

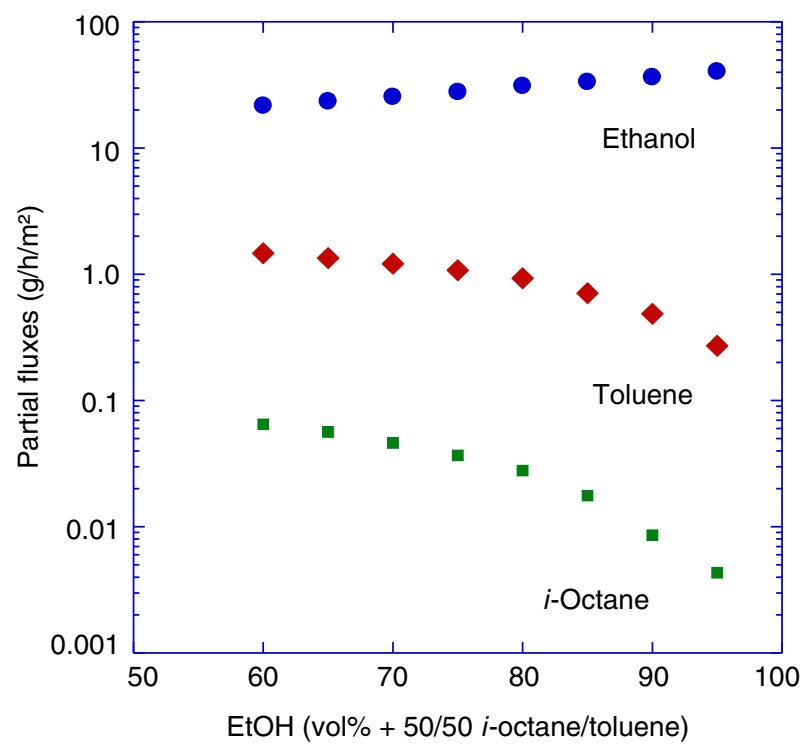

Figure 6

Partial fluxes of a preconditioned EVOH film of $9 \mu \mathrm{m}$ for model fuel mixtures ethanol $/ i$-octane/toluene $(x / y / y$ vol\%) corresponding to the ethanol tie line at $50^{\circ} \mathrm{C}$.

For the toluene tie line, several attempts were then made to measure the permeability properties of EVOH films of $9 \mu \mathrm{m}$, which would have allowed a straightforward comparison with the latter results obtained with the ethanol tie line. Unfortunately, these very thin EVOH films did not withstand continuous exposure to the new model fuel mixtures during permeability measurements and EVOH films of $24 \mu \mathrm{m}$ were eventually used for the toluene tie line. Figure 7 showed that the progress made with the new permeameter found its limits in these conditions. Above a toluene content of $40 \%$, the $i$-octane fluxes could no more be measured accurately and the same limitations as formerly reported by Nulman et al. [9] and Lagaron et al. [10] were thus also encountered in this new composition range. The permeability results obtained with the toluene tie line again showed that ethanol permeated at least ten times faster than toluene over the whole composition range. Furthermore, the toluene flux reached a maximum for a toluene content of ca. $30 \%$ and then decreased by a factor of almost ten when the toluene content further increased from 30 to $100 \%$. This maximum revealed a strong positive synergy between the ethanol and toluene fluxes. The plasticization of EVOH by ethanol, which will be analyzed in the next section, was responsible for this strong synergy and for the toluene flux maximum. Consequently, the EVOH barrier properties were strongly decreased in presence of ethanol in good agreement with 


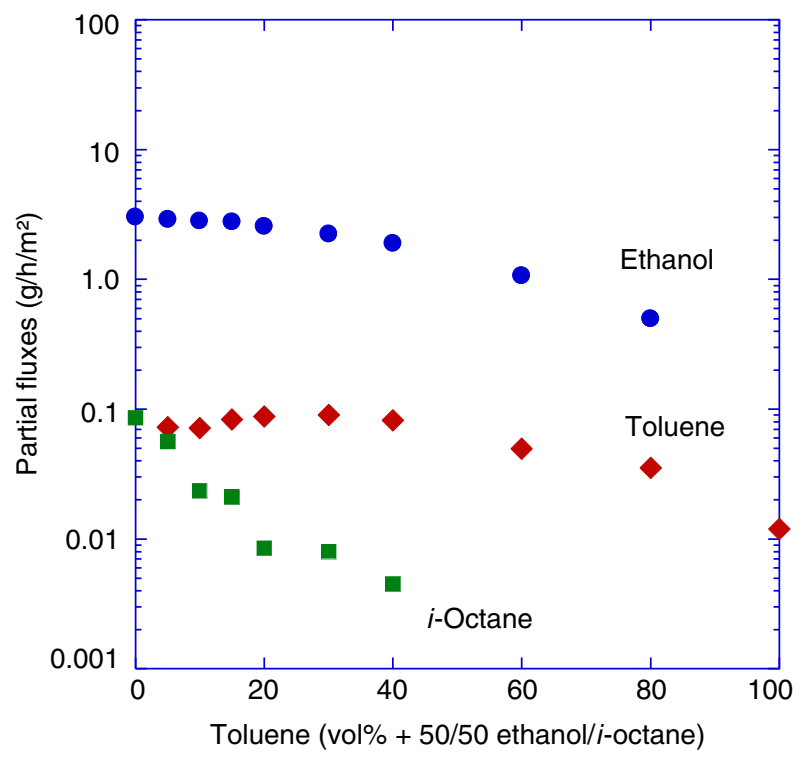

Figure 7

Partial fluxes of a preconditioned EVOH film of $24 \mu \mathrm{m}$ for model fuel mixtures ethanol/i-octane/toluene $(x / x / y \mathrm{vol} \%)$ corresponding to the toluene tie line at $50^{\circ} \mathrm{C}$.

the related observation reported by Lagaron et al. [10] for the addition of $10 \%$ of ethanol to Fuel $\mathrm{C}$ and with other data on the related influence of other protic species (water and methanol) on EVOH permeability [8-11].

For both tie lines covering a wide range of the compositions typically found in the targeted application, ethanol was by far the most preferentially permeated species through the EVOH films and the permeate generally contained over $90 \mathrm{wt} \%$ of ethanol. The role of ethanol was also important on the toluene flux and the related plasticization decreased the EVOH barrier performance towards aromatics. The addition of increasing contents of (bio)ethanol in fuels could thus have important consequences on the barrier properties of multi-layer fuel tanks.

\subsection{Influence of EVOH Conditioning in Model Fuel Mixtures}

This section focuses on the influence of EVOH conditioning on its physical properties and its microstructure, and further illustrates the specific behavior of $\mathrm{EVOH}$ in presence of ethanol oxygenated fuels with respect to the targeted application. Solvent induced changes were assessed by three complementary techniques DSC, WAXS and DMTA. The DSC and WAXS analyses were performed with films of about $10 \mu \mathrm{m}$, which corresponded to the thickness of the polymer film used for
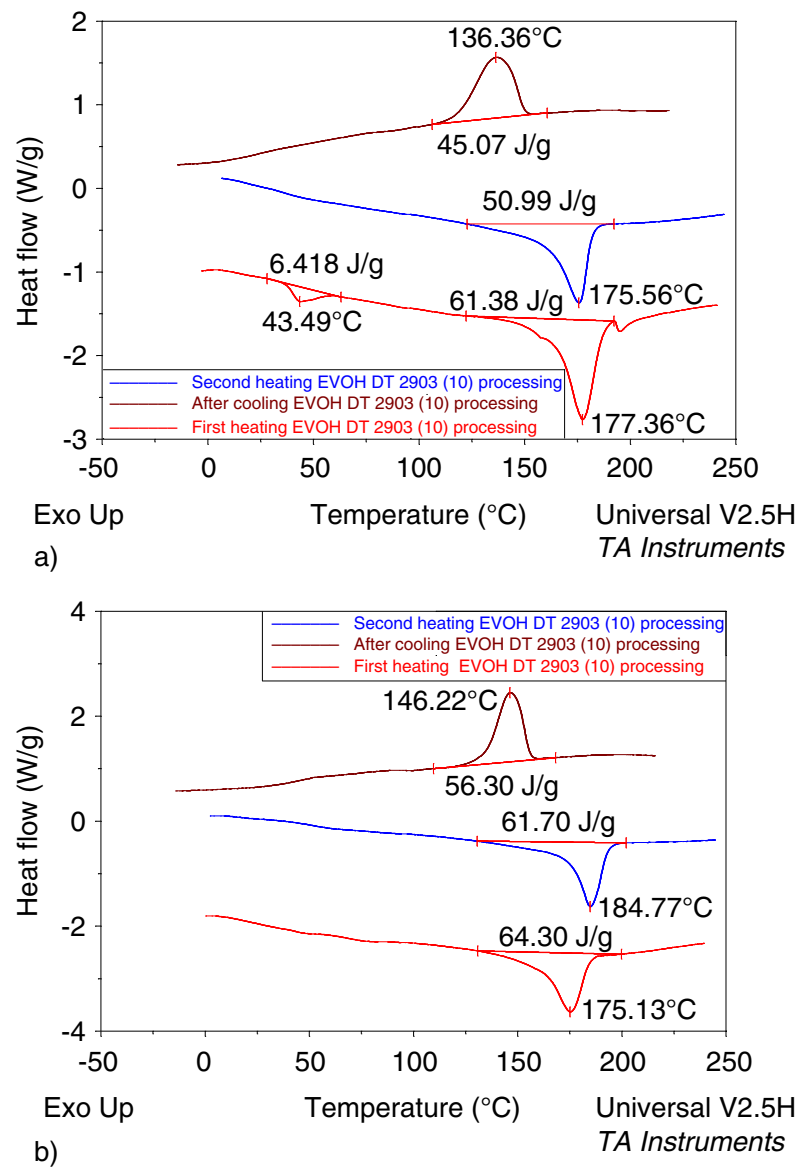

Figure 8

Comparison between the DSC curves obtained for an EVOH film of $10 \mu \mathrm{m}$ a) before conditioning and b) after conditioning. First heating (red), second heating (blue), after cooling (black).

the most challenging ethanol tie line (i.e. the most interesting case with respect to recent evolutions in oxygenated fuels). Unfortunately, the sensitivity of DMTA analysis was too low to assess the mechanical property variations for such thin films and much thicker films of $60 \mu \mathrm{m}$ had to be used to obtain enough sensitivity for this technique. New DSC and WAXS analyses performed for these thicker films could have revealed small differences due to slightly different processing conditions, which were not assessed in this work.

A comparison was first made between the DSC curves obtained for an EVOH film of $10 \mu \mathrm{m}$ before and after its conditioning in the model fuel mixture ethanol/i-octane/ toluene $\left(85 / 7.5 / 7.5-\right.$ Fuel CE85) at $40^{\circ} \mathrm{C}$ until saturation (Fig. 8). The temperature for sample conditioning in this part of the work was slightly different from that used for 

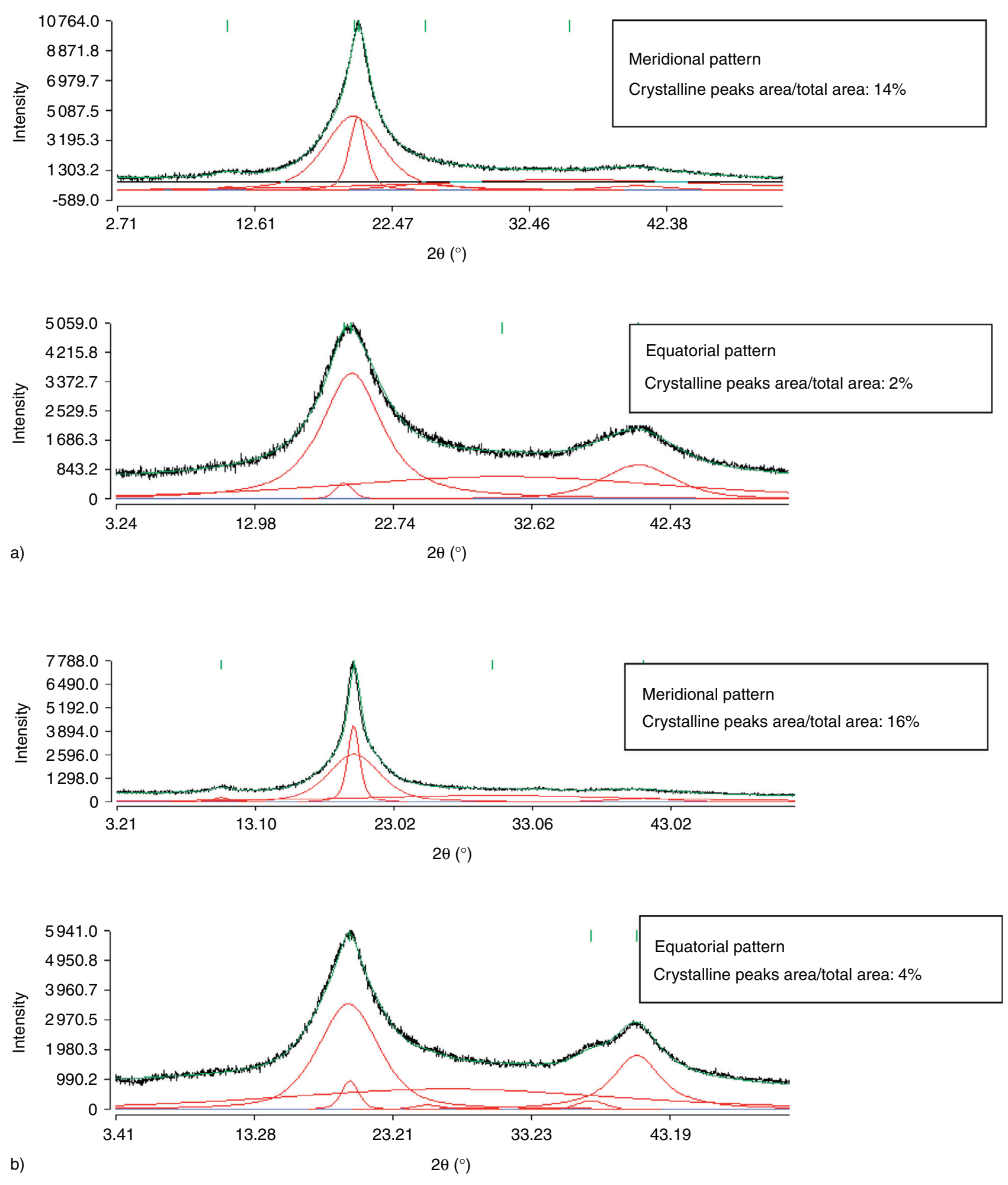

Figure 9

Meridional and equatorial WAXS patterns obtained for an EVOH film of $10 \mu \mathrm{m}$ a) before conditioning and b) after conditioning. 
TABLE 3

WAXS data obtained for an EVOH film of $10 \mu \mathrm{m}$ before and after conditioning

\begin{tabular}{|c|c|c|c|c|c|}
\hline & \multicolumn{2}{|c|}{ Crystalline peak (101) } & \multicolumn{2}{|c|}{ Amorphous bump } & \multirow{2}{*}{$\begin{array}{l}\text { Ratio of the crystalline } \\
\text { peaks area to the total } \\
\text { area }(\%)\end{array}$} \\
\hline & Position $(\AA)$ & Width & Position $(\AA)$ & Width & \\
\hline $\begin{array}{l}\text { Virgin EVOH film } \\
\text { (Meridional) }\end{array}$ & 4.42 & 1.5 & 4.49 & 4.9 & 14 \\
\hline $\begin{array}{l}\text { Virgin EVOH film } \\
\text { (Equatorial) }\end{array}$ & 4.5 & 1.5 & 4.49 & 5.2 & 2 \\
\hline $\begin{array}{l}\text { EVOH film after } \\
\text { conditioning } \\
\text { (Meridional) }\end{array}$ & 4.40 & 1 & 4.40 & 4.4 & 16 \\
\hline $\begin{array}{l}\text { EVOH film after } \\
\text { conditioning } \\
\text { (Equatorial) }\end{array}$ & 4.40 & 1.47 & 4.42 & 5.2 & 4 \\
\hline
\end{tabular}

the permeability experiments due to practical reasons. This particular mixture was chosen because it corresponded to the model fuel mixture for Superethanol $\mathrm{E} 85$, i.e. the most challenging ethanol oxygenated fuel used in the European Union (EU) and the United States of America (USA). The ethanol content of E85 varies between $65 \%$ and $85 \%$ in winter and summer, respectively, and E85 can only be used in so-called "flexiblefuel" cars. The DSC results did not show important differences in terms of crystallinity for EVOH before and after conditioning in Fuel CE85. The thermograms showed similar melting temperatures and a crystallinity of ca. $30 \%$ was found for both samples. Nevertheless, a small increase in the melting enthalpy from 51 to $62 \mathrm{~J} / \mathrm{g}(+22 \%)$ was observed in the second heating after conditioning. Upon cooling, the crystallization temperature was enhanced by $10^{\circ} \mathrm{C}$ after conditioning and the corresponding crystallization enthalpy slightly increased $(+25 \%)$. Furthermore, the small peak at $43.5^{\circ} \mathrm{C}$ for virgin $\mathrm{EVOH}$ was ascribed to slight physical aging during its storage in ambient conditions and disappeared after the first heating, as expected.

WAXS experiments were carried out in transmission mode to complement the latter DSC analysis. EVOH films of $10 \mu \mathrm{m}$ were analyzed before and after conditioning in the same model mixture Fuel CE85. For the WAXS analysis, eight EVOH films had to be stacked together to obtain a sufficient signal. Figure 9 shows representative meridional and equatorial WAXS patterns before and after conditioning. The strong differences for the meridional and equatorial patterns obtainedproved the strong anisotropy of the EVOH films. The crystallinity degree cannot be calculated from WAXS data when samples are oriented. Nevertheless, deconvolution of the WAXS patterns was performed to assess the ratio of the crystalline peaks area to the total area (Tab.3). Even if the limits of the deconvolution method can be debated, deconvolution enabled to compare the results obtained in the same deconvolution conditions and to show that conditioning in Fuel CE85 had only a small influence on EVOH morphology. The results reported in Table 3 confirmed that, if the ratio of the crystalline peaks area to the total area strongly depended upon the observation direction ( $c a .15 \%$ and $4 \%$ in meridional and equatorial directions, respectively), it did not vary significantly after conditioning. Whatever the diffraction pattern, the position of the principal peak did not change. The single small change was the decrease of its width after conditioning, which reflected a small increase in the crystallite size. Furthermore, the WAXS results reported in Table 3 also showed that there was no significant change in the amorphous phase after conditioning. Globally, the WAXS data confirmed the DSC results and showed a slight increase in the ratio of the crystalline peaks area to the total area after conditioning. The later results obtained with Fuel CE85 strongly differed from those formerly reported by Lopez-Rubio et al. [5] on important morphological alterations of EVOH induced by severe hydro-thermal treatments, which were typical for decontamination procedures used in packaging applications. Importantly for multi-layer fuel tanks, EVOH conditioning in the most challenging model Fuel CE85 had a weak influence on its morphology and only induced a small increase in the ratio of the crystalline peaks area to the total area and in the crystallite size.

DMA and DMTA analyses were then performed to assess the influence of EVOH conditioning on its mechanical and physical properties, following the pioneering work of Samus and Rossi [8] on the influence 


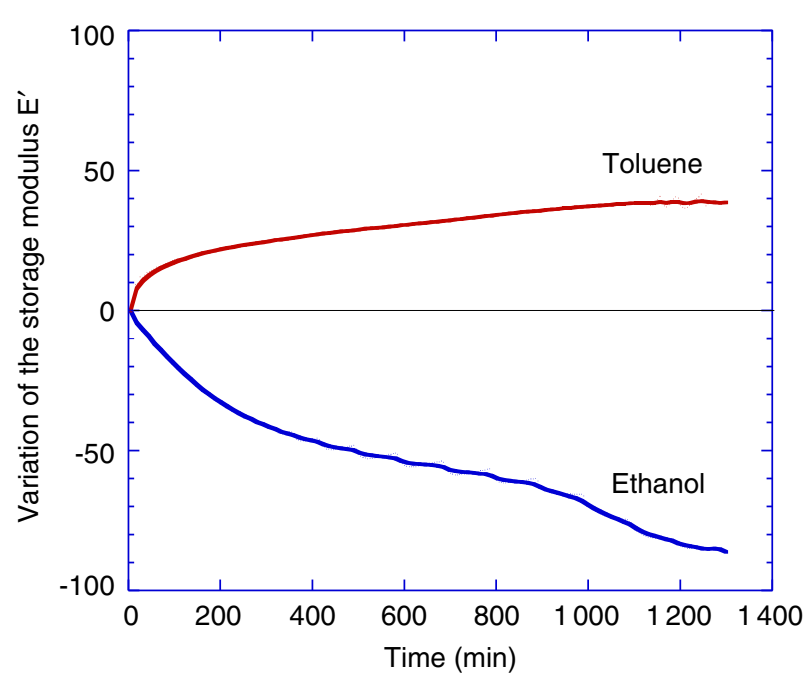

Figure 10

Variation of the storage modulus $E^{\prime}$ of an EVOH film of $60 \mu \mathrm{m}$ during its conditioning in pure toluene and pure ethanol.

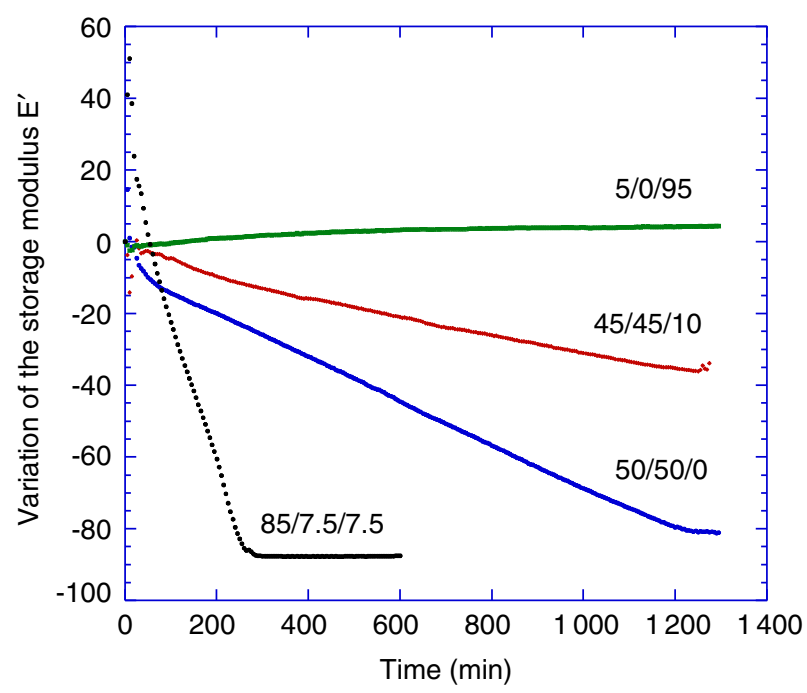

Figure 11

Variation of the storage modulus $E^{\prime}$ of an EVOH film of $60 \mu \mathrm{m}$ during its conditioning in model fuel mixtures ethanol $/ i$-octane/toluene with increasing ethanol contents. of methanol absorption on EVOH mechanical properties and the related changes in methanol diffusion behavior. In the later work, the authors have shown that methanol strongly plasticized $\mathrm{EVOH}$, resulting in a $T_{g}$ decrease of $-10^{\circ} \mathrm{C}$ per weight percent of absorbed methanol. This strong plasticizing effect was related to a sharp increase in methanol diffusion. In our work, the variation of the storage modulus $E^{\prime}$ was first followed over time for $\mathrm{EVOH}$ films of $60 \mu \mathrm{m}$ immersed in pure ethanol and toluene at $23^{\circ} \mathrm{C}$. This temperature corresponded to ambient temperature chosen for practical reasons. The thickness of the films was chosen to obtain enough sensitivity for the dynamic mechanical analysis at a frequency of $1.6 \mathrm{~Hz}$.

Figure 10 shows that very different trends were found for both pure solvents. In the same way as reported by Samus and Rossi [8] for methanol during static experiments, ethanol induced a strong continuous decrease of the storage modulus $(-90 \%)$ in ca. 20 hours and thus strongly plasticized the tested films over a very long period of time. The DMA data also showed that the plasticizing effect of $\mathrm{EVOH}$ still continued after 10 hours in pure ethanol. This alcohol interacted with the EVOH hydroxyl groups and limited the intermolecular interactions in this material. On the other hand, the storage modulus $E^{\prime}$ increased during $\mathrm{EVOH}$ conditioning in pure toluene and reached a plateau at $+40 \%$ after 20 hours. Therefore, pure toluene acted as an efficient anti-plasticizer in EVOH by reinforcing its intermolecular interactions.
Further DMA experiments carried out with model fuel mixtures with increasing ethanol contents showed that the influence of ethanol globally dominated the solvent induced changes at ambient temperature (Fig. 11). Adding $5 \%$ of ethanol to toluene (corresponding to the model fuel mixture 5/0/95) was sufficient to almost compensate for the anti-plasticizing effect of toluene and the increase of the storage module $E^{\prime}$ was very strongly reduced in these conditions. Further increased ethanol contents led to a strong decrease of the storage module over time. Despite the initial artifact of the DMA run in this case, the results obtained for the model Fuel CE85 revealed the strongest influence on EVOH mechanical properties. In this worst case corresponding to the most challenging fuel currently used in the EU and in the USA, the decrease of the storage module was very important and almost similar to that obtained for pure ethanol.

Complementary DMTA experiments enabled to further investigate the influence of EVOH conditioning on its main transition temperature $T_{\alpha}$. After conditioning in pure solvents or in model fuel mixtures with different ethanol contents at ambient temperature, the samples were analyzed in presence of the conditioning medium at a frequency of $1.6 \mathrm{~Hz}$ with a small heating rate of $2^{\circ} \mathrm{C} / \mathrm{min}$ from $-30^{\circ} \mathrm{C}$ to $80^{\circ} \mathrm{C}$. Even if it would have been interesting to investigate temperatures higher than $80^{\circ} \mathrm{C}$ to enable the full determination of the $\alpha$ relaxation of the neat EVOH film, the upper temperature had to be limited in this work for safety reasons due to the handling of fuel model mixtures containing ethanol. 


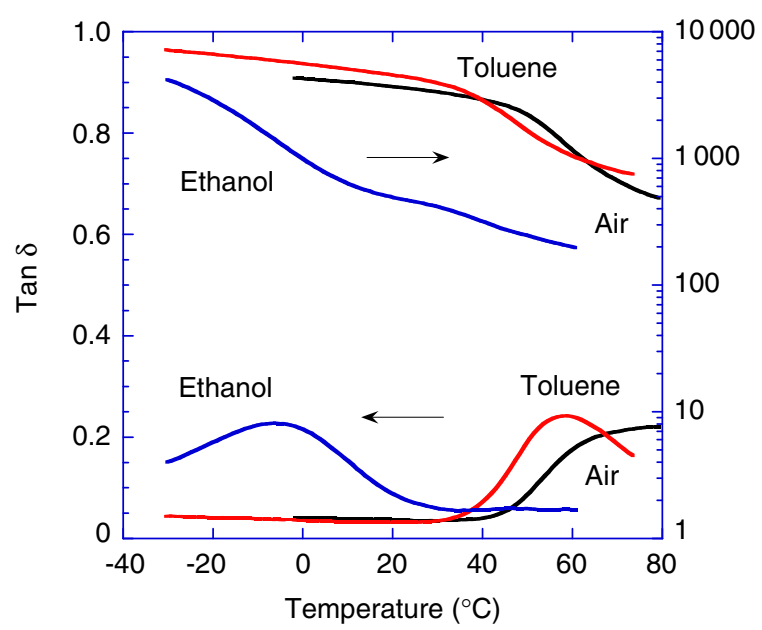

Figure 12

Variation of the loss factor $\tan \delta$ and of the storage module E' of an EVOH film of $60 \mu \mathrm{m}$ after its conditioning in pure toluene and pure ethanol.

Figure 12 shows the variation of the loss factor $\tan \delta$ and the storage module $E^{\prime}$ as a function of temperature for EVOH samples conditioned in pure ethanol and in pure toluene in comparison with virgin EVOH. EVOH conditioning in pure ethanol induced a very strong decrease of its main transition temperature $T_{\alpha}$ from ca. $75^{\circ} \mathrm{C}$ to ca. $-5^{\circ} \mathrm{C}$. This important shift of $T_{\alpha}$ of ca. $-80^{\circ} \mathrm{C}$ was similar to the corresponding shift reported by Samus and Rossi [8] for an EVOH extruded film after its conditioning in methanol while Lagaron et al. [10] reported an even lower $T_{g}$ of $-25^{\circ} \mathrm{C}$ for another methanol-saturated EVOH sample. Our new results confirmed the very strong plasticizing effect of ethanol on $\mathrm{EVOH}$, which was also responsible for a strong decrease in the storage modulus $E^{\prime}$. Compared to ethanol, toluene led to a much smaller impact on $T_{\alpha}$ corresponding to a decrease of less than $20^{\circ} \mathrm{C}$. This small decrease indicated that short scale motions were slightly improved by toluene absorption. Nevertheless, toluene swelling also improved intermolecular interactions in $\mathrm{EVOH}$, which resulted in a higher storage modulus $E^{\prime}$ at ambient temperature (Fig. 12). Therefore, a small decrease in $T_{\alpha}$ co-existed with a significant increase in storage modulus at ambient temperature when EVOH was immersed in pure toluene. This particular behavior confirmed the anti-plasticizing effect of toluene at ambient temperature already observed in Figure 10.

When EVOH conditioning was performed in model fuel mixtures with increasing ethanol contents at ambient temperature, the DMTA patterns were more

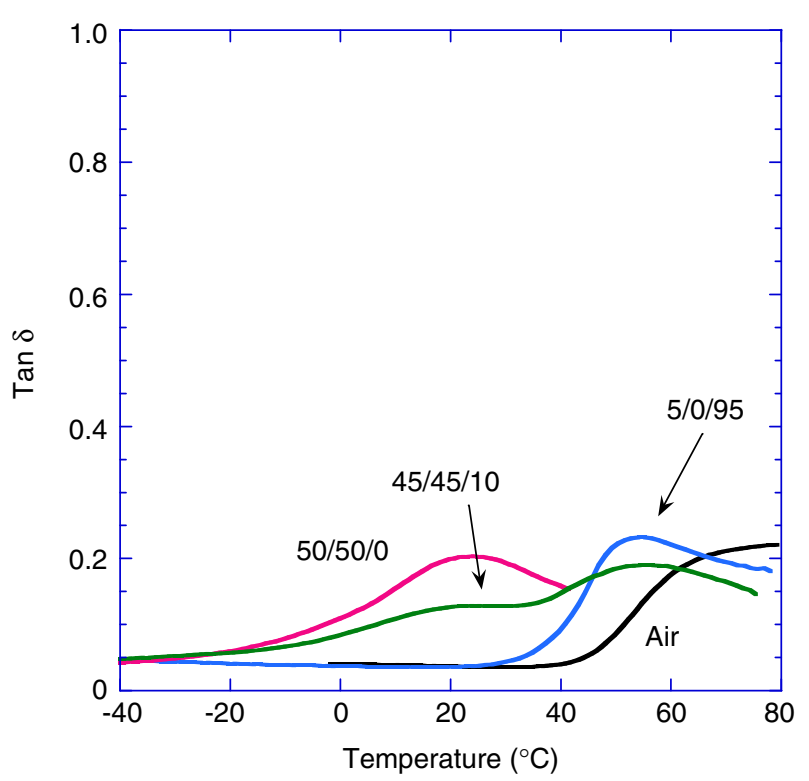

Figure 13

Variation of the loss factor $\tan \delta$ of an EVOH film of $60 \mu \mathrm{m}$ after its conditioning in model fuel mixtures ethanol/i-octane/toluene with increasing ethanol contents.

complex (Fig. 13). Nevertheless, the main transition temperature $T_{\alpha}$ was considerably lowered in presence of oxygenated model fuels and typically decreased when the ethanol content increased. It is important to note that, for several systems, the main transition temperature $T_{\alpha}$ was very close to the temperature of $50^{\circ} \mathrm{C}$ chosen for the permeability measurements. It means that the physical properties of $\mathrm{EVOH}$ could vary strongly close to $50^{\circ}$ $\mathrm{C}$, depending on the composition of the model fuels. This influence was the strongest for the ethanol tie line, which typically corresponded to the strongest ethanol plasticizing effect and to the highest fluxes.

\section{CONCLUSION}

A new automated permeameter was developed for measuring minute quantities as low as $1 \mathrm{mg} /\left(\mathrm{m}^{2}\right.$.day) for partial fluxes with model fuel mixtures containing ethanol, $i$-octane and toluene at $50^{\circ} \mathrm{C}$. With this experimental set-up, it was possible to access to new permeability data and, in some cases, to $i$-octane partial fluxes which have never been reported for EVOH copolymers so far. However, the obtaining of accurate data necessitated an EVOH preconditioning in the model fuel mixtures to avoid the long drifts in the permeability data over time, which were initially obtained for virgin EVOH samples. 
Permeability data were obtained for two important tie lines (i.e. ethanol and toluene tie lines) in the ternary diagram ethanol $/ i$-octane/toluene. The partial flux of ethanol was systematically ca. ten times higher than that of toluene and ca. hundred times higher than that of $i$-octane. Therefore, the permeate samples generally contained at least $90 \mathrm{wt} \%$ of ethanol and this alcohol can thus be considered as a key component for EVOH permeability. Ethanol also played a strong role on EVOH conditioning in the oxygenated model mixtures. Its strong plasticizing effect led to a strong decrease in the EVOH mechanical and physical properties. However, ethanol did not induce any significant change in $\mathrm{EVOH}$ crystallinity.

Globally, ethanol induced a strong increase in EVOH total permeability. The role of ethanol was also important on the toluene flux and the related plasticization effect decreased the EVOH barrier performance towards aromatics. The addition of increasing contents of (bio) ethanol in fuels could thus have important consequences on the barrier properties of multi-layer fuel tanks. The new metrology developed in this work offers a new insight in the EVOH permeability properties and will help prevent the consequences of (bio)ethanol addition in fuels on environmental emissions through fuel lines and tanks.

\section{ACKNOWLEDGMENTS}

Jing Zhao and his colleagues gratefully acknowledge the support of the chemical company Arkema.

\section{REFERENCES}

1 Khanah Mokwena K., Tang J. (2012) Ethylene Vinyl Alcohol: A Review of Barrier Properties for Packaging Shelf Stable Foods, Crit. Rev. Food Sci. Nutrition 52, 6405-650.

2 Apicella A., Hopfenberg H.B. (1982) Water-swelling behavior of an ethylene-vinyl alcohol copolymer in presence of sorbed sodium chloride, J. Appl. Polym. Sci. 27, 1139-1148.

3 Aucejo S., Pozo M.J., Gavara R. (1998) Effect of water presence on the sorption of organic compounds in ethylene-vinyl alcohol copolymers, J. Appl. Polym. Sci. 70, 711-716.
4 Zhang Z., Britt I.J., Tung M.A. (1999) Water Absorption in EVOH Films and Its Influence on Glass Transition Temperature, J. Polym. Sci. Part B Polym. Phys. 37, 691-699.

5 Lopez-Rubio A., Lagaron J.M., Giménez E., Cava D., Hernandez-Munoz P., Yamamoto T., Gavara R. (2003) Morphological alterations induced by temperature and humidity in ethylene-vinyl alcohol copolymers, Macromolecules 36, 9467-9476.

6 Zhang Z., Britt I.J., Tung M.A. (2001) Permeation of oxygen and water vapor through EVOH films as influenced by relative humidity, J. Appl. Polym. Sci. 82, 1866-1872.

7 Cava D., Lagaron J.M., Martinez-Gimenez F., Gavara R. (2007) Inverse gas chromatography study on the effect of humidity on the mass transport of alcohols in an ethylene-vinyl alcohol copolymer near the glass transition temperature, J. Chromatogr. A 1175, 267-274.

8 Samus M.A., Rossi G. (1996) Methanol absorption in ethylene-vinyl alcohol copolymers: Relation between solvent diffusion and changes in glass transition temperature in glassy polymeric materials, Macromolecules 29, 2275-2288.

9 Nulman M., Olejnik A., Samus M., Fead E., Rossi G. (1998) Fuel permeation performance of polymeric materials analyzed by gas chromatography and sorption techniques, SAE Special Publications 1365, 41-47.

10 Lagaron J.M., Powell A.K., Bonner G. (2001) Permeation of water, methanol, fuel and alcohol-containing fuels in high-barrier ethylene-vinyl alcohol copolymer, Polym. Testing 20, 569-577.

11 Gagnard C., Germain Y., Keraudren P., Barriere B. (2004) Permeability of semicrystalline polymers to toluene/methanol mixture, J. Appl. Polym. Sci. 92, 676-682.

12 Clément R., Kanaan C., Brulé B., Lenda H., Lochon P., Jonquières A. (2007) An original automated desorption apparatus for measuring multi-component sorption properties of barrier polymer films, J. Membr. Sci. 302, 95-101.

13 Smitha B., Suhanya D., Sridhar S., Ramakrishna M. (2004) Separation of organic-organic mixtures by pervaporation A review, J. Membr. Sci. 241, 1-21.

14 Garcia Villaluenga J.P., Tabe-Mohammadi A. (2000) A review on the separation of benzene/cyclohexane mixtures by pervaporation processes, J. Membr. Sci. 169, 159-174.

15 Uragami T. (2006) Polymer Membranes for Separation of Organic Liquid Mixtures - Chapter 14 in Materials Science of Membranes for Gas and Vapor Permeation, Yampolskii Y., Pinnau I., Freeman B.D. (eds), John Wiley \& Sons, New York, pp. 355-371.

16 Iwanami T., Hirai Y. (1983) Ethylene vinyl alcohol resins for gas-barrier material, Tappi J. 66, 85-90.

Manuscript accepted in July 2013 Published online in November 2013

Cite this article as: J. Zhao, C. Kanaan, R. Clément, B. Brulé, H. Lenda and A. Jonquières (2015). Permeability of EVOH Barrier Material Used in Automotive Applications: Metrology Development for Model Fuel Mixtures, Oil Gas Sci. Technol 70, 2, 353-366. 